\title{
The psychological distress in students during the COVID-19 crisis: An 8-wave longitudinal study
}

\author{
Anita Vulić-Prtorić ${ }^{1 *}$, Matea Bodrožić Selak ${ }^{1}$, Paola Sturnela ${ }^{1}$ \\ Department of Psychology, University of Zadar, Croatia \\ * Correspondence: Anita Vulić-Prtorić, avulicp@gmail.com
}

\begin{abstract}
The aim of this study is to investigate the changes in psychological distress during initial stage of the coronavirus pandemic in Croatia. The sample consisted of 363 students with an average age of 23.42 years. The results show that students in Croatia reported average levels of depression, anxiety and stress, with no differences in the degree of psychological distress between the pre-pandemic period and the pandemic period. Of the respondents, $19.48 \%$, $28.8 \%$ and $22.08 \%$ respectively reported moderate to severe depression, anxiety and stress, which remained largely stable during the survey period. All significant differences during the 8-week period show that depression, anxiety and stress generally decrease over time.
\end{abstract}

Keywords: COVID -19 pandemic, depression, anxiety, stress, students

\section{INTRODUCTION}

Although students are not the primary risk population in the COVID-19 pandemic (such as infected patients, people in quarantine or healthcare workers), they are at high risk for various mental health problems due to the multiple stressors in this stage of life (Beiter et al., 2015). In addition, in some cases it has been found that economic and social factors were more strongly and consistently associated with emotional stress during the COVID-19 pandemic than exposure to viral health risks (Shanahan et al., 2020). The COVID-19 pandemic brought many additional sources of stress, and all these stressful normative transitions are grouped together as COVID-19-related stressors: concerns about one's own health risks and those of loved ones, abnormally reduced social contacts with others, separation from friends and family, loss of freedom, closure of universities, online education, etc. They appear to be associated with feelings of frustration and insecurity and to have negative effects on mental health and well-being (Cao et al., 2020; Liang et al., 2020; RithNajarian et al., 2019; Serafini et al., 2020; Shanahan et al., 2020; Zivin et al., 2009; Wang and Zhao, 2020). Some previous studies pointed to an increased psychological burden during the pandemic in the samples of young adults: in the representative sample of university students in China, Wang and Zhao (2020) found that their participants experienced higher levels of anxiety than the general population after the outbreak of COVID -19; in the university community during the first weeks of confinement in Spain, Odriozola-Gonzáleza et al. (2020) observed higher levels of depression, anxiety and stress among students compared to the university workers; and the study by Kazmi et al (2020) in India found that depression, anxiety and stress were more common among participants aged 15-35 years. 
The students' ability to cope with the pandemic and to effectively and appropriately regulate their emotions and behavior during the pandemic could have a significant impact on their long-term academic, social and mental health outcomes. On the other hand, young adults (and even more students) have the potential and resilience resources compared to others: they are not at risk of health complications, they are very informed and competent in dealing with social media and usually do not need to care for children or parents. This was the reason for the research on how the change in lifestyle in the early stages of the coronavirus pandemic in Croatia would affect university students and whether the corona crisis and quarantine (lockdown) would increase or decrease their stress, anxiety and depression?

The results reported in this paper are part of a larger ongoing longitudinal study entitled Pandemic and I on the psychological aspects of the COVID-19 pandemic among Croatian university students. The study began in the first week of the nationwide lockdown (announced on 16 March). We continued surveying the same population during the lockdown, i.e. in the following 8 weeks. The major COVID-19 related events during this period are shown in Table 1. The plan for this ongoing longitudinal project is to conduct the next waves of the survey on the $3^{\text {rd }}, 6^{\text {th }}$ and $12^{\text {th }}$ month after the last week of the survey to investigate possible changes in mental health in the same sample of university students.

As numerous cross-sectional epidemiological studies with different psychological consequences have been published since the outbreak of pandemic COVID-19 (Brooks et al., 2019; Kontoangelos et al. 2020; Serafini et al. 2020; Verma and Mishra, 2020), we have focused in this study on two specific study objectives: to compare the results of the selfassessment of DASS-21 results before and during pandemic; to conduct a longitudinal study to monitor changes in DASS-21 results during the 8-week period of the lockdown.

First, it is important to compare the data collected before and during the pandemic if we are to draw conclusions about changes in mental health. Although the results in most studies show that there are many negative psychological consequences of the pandemic, there are also some different findings. For example, Shanahan et al (2020) compared emotional stress in young adults during the COVID-19 pandemic and two years before. They found an increased level of perceived stress and anger during the pandemic, but no differences in internalizing symptoms. The first aim of this study was to find out whether the level of psychological distress (depression, anxiety and stress) changed during the COVID-19 lockdown compared to the time before the pandemic. The hypothesis was that the psychological distress would be higher during the time of the corona crisis.

Secondly, many studies in the field are based on cross-sectional study designs and they cannot identify the psychological impact during the different periods of the pandemic (at the beginning, in the middle, at the end and even some short or long time after the outbreak). This means that longitudinal study designs with assessments on the same participants at different times during the pandemic are required. Accordingly, we designed an ongoing longitudinal panel study with the eight waves conducted in Croatia during the initial phase of the lockdown period. In this case, we hypothesized that the psychological distress would be higher at the beginning of this period. Furthermore, based on the theoretically well-founded DASS-21 constructs, we expected a relatively stable pattern at the individual levels of anxiety, depression and stress during the same study period (Kendler et al., 2012; Lovibond, 1998). 
Table 1 COVID-19 related events in Croatia and national epidemic statistics during the target period of survey

\begin{tabular}{|c|c|c|c|c|c|}
\hline \multirow[b]{2}{*}{$\begin{array}{l}\text { Study } \\
\text { Wave }\end{array}$} & \multirow[b]{2}{*}{ Week } & \multirow[b]{2}{*}{ COVID-19 related events } & \multicolumn{3}{|c|}{$\begin{array}{c}\text { COVID-19 8-WEEK STATISTICS IN } \\
\text { CROATIA } \\
\end{array}$} \\
\hline & & & Confirmed & Recovered & Deaths \\
\hline 1 & $\begin{array}{c}\text { March } 13- \\
20^{\text {th }}\end{array}$ & $\begin{array}{l}\text { Closing schools, universities, } \\
\text { cafes, restaurants, cinemas, } \\
\text { theaters, etc. } \\
\text { Beginning of online teaching for } \\
\text { all educational levels. }\end{array}$ & 106 & 4 & 0 \\
\hline 2 & $\begin{array}{c}\text { March } 20- \\
27^{\text {th }}\end{array}$ & $\begin{array}{l}\text { Closure of bus stations and } \\
\text { intercity traffic. } \\
\text { Strong earthquake in Zagreb. } \\
\text { Ban of leaving the place of } \\
\text { residence. } \\
\text { The first death was caused by a } \\
\text { coronavirus infection in Croatia. }\end{array}$ & 526 & 47 & 3 \\
\hline 3 & $\begin{array}{c}\text { March } 27^{\text {th }}- \\
\text { April } 03^{\text {rd }}\end{array}$ & $\begin{array}{l}\text { The highest increase in newly } \\
\text { infected cases so far ( } 96 \text { in } 24 \\
\text { hours). }\end{array}$ & 470 & 44 & 4 \\
\hline 4 & $\begin{array}{l}\text { April } 03- \\
\quad 10^{\text {th }}\end{array}$ & $\begin{array}{l}\text { Organized return of Croatian } \\
\text { citizens from European } \\
\text { countries ( } 148 \text { students). } \\
\text { Coronavirus infection in nursing } \\
\text { homes. }\end{array}$ & 436 & 147 & 14 \\
\hline 5 & $\begin{array}{l}\text { April } 10- \\
17^{\text {th }}\end{array}$ & $\begin{array}{l}\text { A declining trend in the number } \\
\text { of newly infected. }\end{array}$ & 254 & 452 & 15 \\
\hline 6 & $\begin{array}{l}\text { April } 17- \\
24^{\text {th }}\end{array}$ & $\begin{array}{l}\text { The situation is improving, } \\
\text { mitigation measures are } \\
\text { presented in } 3 \text { phases. }\end{array}$ & 200 & 410 & 14 \\
\hline 7 & $\begin{array}{l}\text { April } 24^{\text {th }}- \\
\quad \text { May } 1^{\text {st }}\end{array}$ & $\begin{array}{l}\text { Beginning of the first phase of } \\
\text { easing the measures. } \\
\text { Opening more stores with } \\
\text { longer working hours. }\end{array}$ & 57 & 413 & 25 \\
\hline 8 & May $1-15^{t h}$ & $\begin{array}{l}\text { Passes for intercity traffic are } \\
\text { being abolished, cafes and } \\
\text { restaurants are being opened. }\end{array}$ & 129 & 394 & 25 \\
\hline
\end{tabular}

The novelty of this study is that it provides data from the longitudinal examination of the temporal mental state of the students in relation to depression, anxiety and stress during the first 8 weeks of lockdown. As far as we know, there has not yet been a longitudinal study of the effects of COVID-19 on this population during the period of confinement. 


\section{METHOD}

\section{Participants and procedures}

In the initial phase of pandemic COVID-19 in Croatia, an 8-wave longitudinal study was designed. The first group of participants was formed within the course of Health Psychology at the University of Zadar, Croatia, as part of the student activities in the times of the COVID19 outbreak. Psychology students $(\mathrm{N}=52)$ were invited to participate in the online project entitled Pandemic and $I$. They were informed that their participation is anonymous and that they can withdraw from the study at any time if they do not wish to participate. The next step was to introduce the partial snowball method: The group of psychology students was asked to contact their acquaintances and friends online (average 7-8 participants). They remained in contact with them throughout the project. The participants came from different parts of Croatia. This created a network of participants who were in contact with each other. They answered weekly online questionnaires and received psychological support through psycho-educational materials thematically related to research and mutual communication. All participants were enrolled through the online survey designed for this study. Before the survey was completed, each participant was informed about the nature of the study and explained that participation in the study implied agreement to analyze their responses. No personally identifiable information was requested from any of the participants. It took approximately 10-15 minutes to complete the survey. The instructions indicated that there was no time limit for answering and that there were no wrong or correct answers.

A total of 363 participants took part in the first wave (293 female and 70 male participants; $\mathrm{M}_{\mathrm{age}}=23.42 ; \mathrm{SD}_{\mathrm{age}}=3.98$ ), but due to the longitudinal nature of the study, there was expected drop-out of participants after the first wave, so the sample of interest in this study consisted of 154 students (132 female and 22 male participants; $M_{\text {age }}=23.07 ; S_{\text {age }}=1.87$ ) who participated in at least 5 of the 8 waves. No significant differences were found between the participants who remained in the study and those who left after the first wave $(F=0.00, d f=1$, $p>.05)$.

The pre- pandemic results are extracted from another research (with cross-sectional design) on physical health and its psychological correlates, conducted at the same Croatian university with the same psychological measurements in the sample of 230 students (210 female and 20 male; $\mathrm{M}_{\mathrm{age}}=21.89 ; \mathrm{SD}_{\mathrm{age}}=3.30$ ). The most recent data in the study mentioned above were collected in December 2019.

Both the surveys and the psychoeducational materials were distributed at weekends to ensure maximum participation. We used a 7-day period because events during this pandemic changed very rapidly over time and this seemed to be the appropriate time period for the symptom measures included in our study (Taylor et al., 2020). The project protocol was approved by the Ethics Committee of the Department of Psychology, University of Zadar.

\section{Measures}

The questionnaire package used in this study consists of three parts: 1) socio-demographic data (gender, age, the city they lived in during the survey); 2) open questions about their COVID-19-related stress perception and stress experiences; 3) measures of anxiety, depression, stress, coping skills, mindfulness, anger, loneliness, cyberchondria, nomophobia, etc.). For the purposes of this paper, only the results of DASS-21 are presented. 
Depression Anxiety and Stress Scale. The global mental health status of participants was measured using the Depression Anxiety and Stress Scale (DASS-21; Lovibond \& Lovibond, 1995), which was previously used in studies on the COVID-19 pandemic (e.g. Wang et al., 2020; Tan et al., 2020; Ozamiz-Etxebarria et al., 2020; Verma and Mishra, 2020; RodriguezRey, Garrido-Hernansaiz and Collado, 2020). DASS-21 is a 21-point self-report instrument consisting of three subscales: depression, anxiety and stress. On a 4-point Likert scale from 0 ("did not apply to me at all") to 3 ("applied to me very often or most of the time"), participants indicate the extent to which a symptom has occurred in the past week. As each subscale consists of 7 items, the total values for depression, anxiety and stress are calculated by the sum of the values of the individual items. In addition, the subscale scores can be assigned to one of the 5 levels of severity- for depression: normal (0-4), mild (5-6), moderate (7-10), severe (11-13) and extremely severe (14+); for anxiety: normal (0-3), mild (4-5), moderate (6-7), severe (8-9) and extremely severe (10+); for stress: normal (0-7), mild (8-9), moderate (10-12), severe (13-16) and extremely severe (17+) (Lovibond \& Lovibond, 1995; Wang et al., 2020)

The DASS-21 is a well validated instrument and has also shown excellent internal consistency in this study (Cronbach's $\alpha$ were $0.87,0.88,0.89,0.95$ for depression, anxiety, stress and total score respectively), which is consistent with previous research studies (Henry and Crawford, 2005; Ozamiz-Etxebarria, et al., 2020).

\section{Data analysis}

The statistical package Statistica 13 was used to perform the statistical analysis. Before further relevant analyzes were performed, the assumptions of normality, precisely skewness, kurtosis, and Kolmogorov-Smirnov statistical tests were obtained (Table 2). As the data show, the Kolmogorov-Smirnov test indicates that the data do not follow a normal distribution in all variables of interest. However, it is important to emphasize that there is support in the literature for the robustness of parametric tests, even if there is a violation of the assumptions of normality, taking into account skewness and kurtosis that did not exceed the value of 3 (Kline, 2011). Therefore, it can be concluded that the use of parametric statistical methods is justified for further data analysis. Descriptive and trend analyzes were conducted to investigate prospective changes in depression, anxiety and stress during first eight weeks of the pandemic among Croatian students.

Table 2 Means, standard deviations, skewness, kurtosis and Kolmogorov-Smirnov statistical tests for depression, anxiety, and stress ( $N=363)$

\begin{tabular}{|l|c|c|c|c|c|c|}
\hline & \multirow{2}{*}{ Mean } & \multirow{2}{*}{ SD } & \multirow{2}{*}{ Skewness } & \multirow{2}{*}{ Kurtosis } & \multicolumn{2}{|c|}{ Kolmogorov-Smirnov test } \\
\cline { 5 - 7 } & & & & & & p-value \\
\hline Depression & 4.16 & 4.41 & 1.44 & 1.73 & .19 & $<.01$ \\
\hline Anxiety & 3.19 & 4.11 & 1.76 & 2.91 & .22 & $<.01$ \\
\hline Stress & 5.82 & 4.95 & 0.79 & 0.03 & .12 & $<.01$ \\
\hline
\end{tabular}

$S D$, standard deviation. 


\section{RESULTS}

In the first step we compared the DASS-21 results from the pre-pandemic sample $(\mathrm{N}=231$; depression scale: $M=4.24$; $S D=3.55$; anxiety scale: $M=3.85$; $S D=3.76$; stress scale: $M=6.35$; $S D=4.50)$ with the results of the first pandemic wave $(N=363$; depression scale: $M=4.16$; $S D$ =4.41; anxiety scale: $M=3.19 ; S D=4.11$; stress scale: $M=5.82 ; S D=4.95)$. The results showed no significant differences in depression, anxiety and stress between the results before and after the onset of the pandemic $(F=2.51, d f=3, p>05)$.

In the current study, when assessing the degree of depression, anxiety and stress levels, it was found that the mean value of the sample was highest on the stress scale, followed by depression and anxiety (Figure 1). Individual subscale scores on the DASS-21 scale can be assigned to one of five severity levels (normal, mild, moderate, severe and extremely severe). Table 2 shows the results of the first wave indicating that most students were between the normal and mild range for depression $(M=4.16$; normal range $=0-4$, mild range $=5-6)$ and anxiety $(M=3.19$; normal range $=0-3$; mild range $=4-5)$. The mean value of the stress score $(M=5.82)$ shows that the results of our participants fell into the normal range (07). About one fifth of the participants were classified as moderately to-severely distressed: depression, anxiety and stress were reported by $19.48 \%, 28.8 \%$ and $22.08 \%$ of the participants respectively (Table 3 ).

Table 3 Number (\%) of participants in each symptoms severity category in the DASS-21 $(\mathrm{N}=154)$

\begin{tabular}{|l|c|c|c|c|c|c|}
\hline & \multicolumn{2}{|c|}{ Depression } & \multicolumn{2}{c|}{ Anxiety } & \multicolumn{2}{c|}{ Stress } \\
\hline & $\mathbf{N}$ & $\mathbf{\%}$ & $\mathbf{N}$ & $\mathbf{\%}$ & $\mathbf{N}$ & $\%$ \\
\hline Normal & 99 & 64.29 & 96 & 62.34 & 98 & 63.64 \\
\hline Mild & 16 & 10.39 & 25 & 16.23 & 13 & 8.44 \\
\hline Moderate & 16 & 10.39 & 5 & 3.25 & 19 & 12.34 \\
\hline Severe & 8 & 5.19 & 7 & 4.55 & 9 & 5.84 \\
\hline Extremely severe & 6 & 3.90 & 12 & 7.79 & 6 & 3.90 \\
\hline
\end{tabular}

In order to analyze the possible changes in the extent of depression, anxiety and stress, we compared the DASS- 21 results collected in eight waves. The distributions of the mean scores on each subscale over time are shown in Figure 1. 


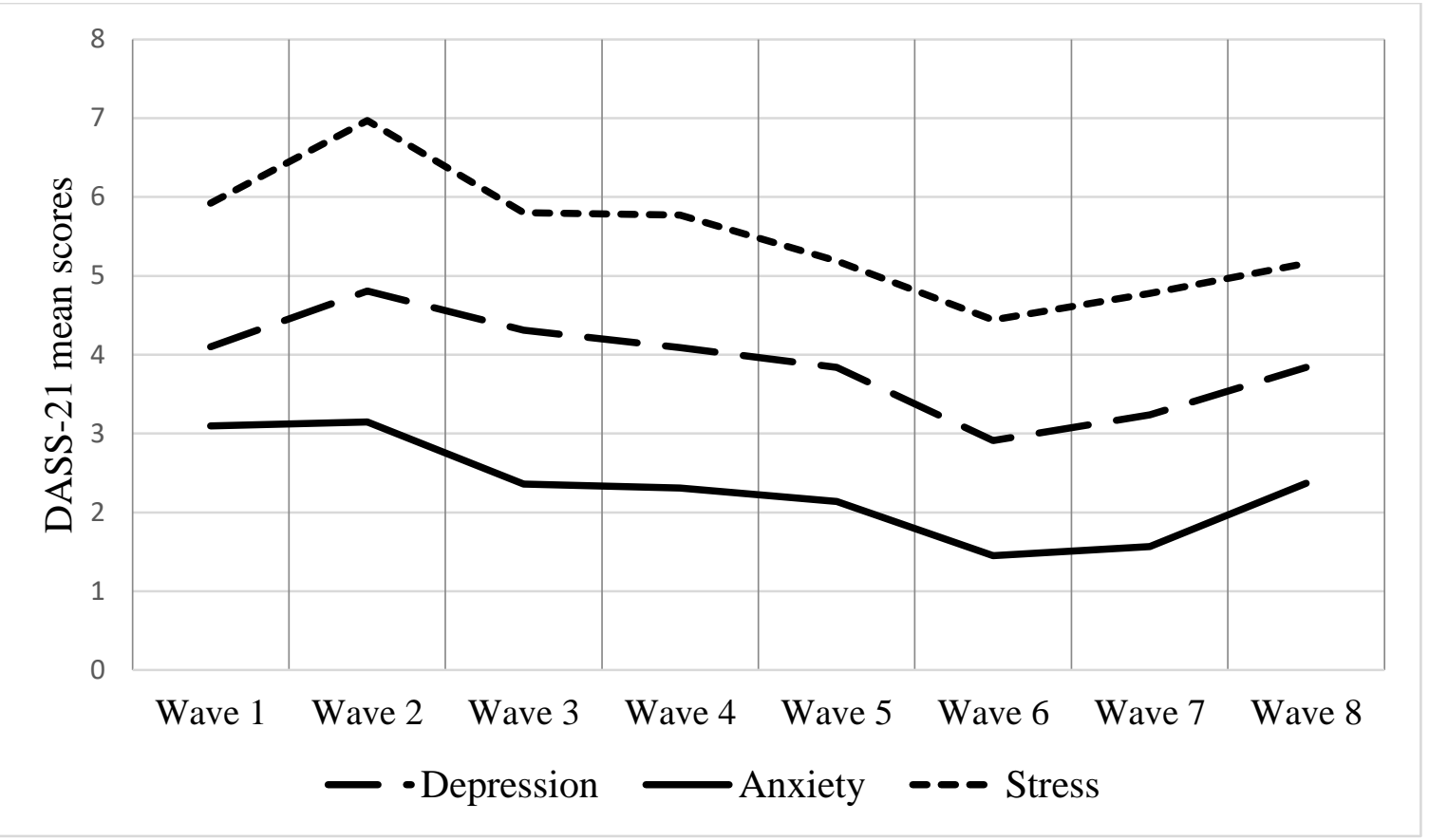

Figure 1 Mean scores on the subscales Depression, Anxiety, and Stress through 8-waves study $(\mathrm{N}=154)$

Possible differences between the results on each subscale by 8 points in time were tested with ANOVA for repeated measurements. According to the results of the statistical analysis performed, there are significant differences in depression levels over 8 weeks $(F=8.18, d f=7$, $p<0.001$ ). The comparison between depression levels in 8 waves shows that depression in the $6^{\text {th }}$ week shows statistically significant differences compared to waves $1,2,3$ and 4 . The reported depression levels in wave 7 also differ from the results in wave 2. All significant differences show that the depression levels decrease over time.

Concerning anxiety levels in 8 waves, the ANOVA analysis showed significant differences $(F=11.46, d f=7, p 0.001)$ between waves 1 and 6 and 7 and between waves 2 and 5, 6, 7. All significant differences show that anxiety levels decrease over time.

Finally, the stress levels show significant differences over time $(F=10.42, d f=7, p<0.001)$. The differences were found between the results in waves 6 and 1, 2, 3, 4 and between wave 2 and 5, 7 and 8 . As in the case of anxiety and depression, the stress levels show a decreasing trend over time.

In the next step, we investigate how many of our participants showed a change in the result trends during the pandemic and how many of them had stable results. For this purpose, the outcome of the severity category for each participant was considered at eight measurement points to examine the trends. There are four result trends based on severity: stable, descending, ascending and oscillating. As Table 4 shows, almost half of the participants experienced a change in the severity of depression, anxiety and stress $(51.95 \%, 50.65 \%$ and $55.84 \%$ respectively). 
Table 4 Number (\%) of participants in each category of the DASS-21 result trends $(N=154)$

\begin{tabular}{|l|c|c|c|c|c|c|}
\hline & \multicolumn{2}{|c|}{ Depression } & \multicolumn{2}{c|}{ Anxiety } & \multicolumn{2}{c|}{ Stress } \\
\hline & $\mathbf{N}$ & $\%$ & $\mathbf{N}$ & $\%$ & $\mathbf{N}$ & $\%$ \\
\hline Stable & 74 & 48.05 & 76 & 49.35 & 68 & 44.16 \\
\hline Descending & 12 & 7.79 & 20 & 12.99 & 9 & 5.84 \\
\hline Ascending & 7 & 4.55 & 4 & 2.60 & 6 & 3.90 \\
\hline Oscillating & 61 & 39.61 & 54 & 35.06 & 71 & 46.10 \\
\hline
\end{tabular}

The participants in this study mostly reported stable and oscillating levels of depression, anxiety and stress during the lockdown. On the other hand, the smallest number of participants reported descending or ascending changes in symptoms at eight measurement points.

\section{DISCUSSION}

The aim of the present study was to investigate the changes in the psychological distress among Croatian students in the early stages of the pandemic COVID-19. The results on DASS21 were analyzed in two steps: The first step was to test the differences in depression, anxiety and stress before and after the outbreak of the COVID pandemic; the second step was to examine the potential changes in depression, anxiety and stress during the eightweek confinement.

The results of the present study suggest that levels of depression, anxiety and stress were normal in more than $60 \%$ of cases during the pandemic (Tables 3 and 4). Moderate- to severe levels of depression, anxiety and stress were found in $19.48 \%, 28.8 \%$ and $22.08 \%$ of the participants, respectively. Unexpectedly, we found no significant differences between the levels of depression, anxiety and stress in the period before the pandemic and during the pandemic. This finding does not support the original hypothesis. It appears that prepandemic stress contributed to the emotional stress among our participants in the same way as COVID-19-related health risk exposure. Some earlier findings also suggest that although many people express emotional stress and some are prone to stress-related psychopathology, most people are resistant to stress, some even report that they feel better during the pandemic than before it (Shanahan et al. 2020; de Quervain et al. 2020; Taylor 2019; Taylor et al. 2020). In their comprehensive study in Croatia, Jokić-Begić et al. (2020) found that $66.1 \%$ of participants rated their mental state as equal, $9.1 \%$ as better and $24.8 \%$ as worse.

These results are consistent with the observations of some studies in Croatia (Roje Đapić et al., 2020) and some studies abroad (Shanahan et al., 2020), which found that internalizing symptoms have the highest stability among the distress indicators. There are several explanations for this finding. First, our participants were not exposed to the most traumatic aspects of the pandemic (such as their infection, the infection of their family/friends or the 
death of relatives due to COVID -19), which is a risk factor for increasing anxiety (Cao et al., 2020). Only one of the 154 participants was infected with the virus during 8 weeks. In the context of other similar studies on the psychological aspects of the pandemic caused by COVID-19, the results of the present study differ slightly from studies abroad, e.g. studies on the Spanish or Chinese population (Rodriguez-Rey, Garrido-Hernansaiz and Colado, 2020; Wang et al., 2020), in which higher levels of depression, anxiety and stress were documented. This was to be expected due to the large number of deaths and infected persons, but also due to behavioral restrictions, lockdown measures and drastically changed living conditions of people living in these countries. If we look, for example, at the results of the studies in which the same psychological instrument (DASS-21) was used, we can observe differences in the extent of distress in different countries: among the participants in Spain, in the study by Ozamiz-Etxebarria et al. (2020), more than a quarter of the general population sample had symptoms of depression (27.5\%), anxiety (26.9\%) and stress ( $26.5 \%$ ), and depending on the circumstances, the authors interpret these results as optimistic; in the general adult population in Spain Rodriguez-Rey, Garrido-Hernansaiz and Collado (2020), $41 \%$ of participants reported depressive symptoms, $25 \%$ showed mild to severe anxiety, and 41\% felt stressed; Verma and Mishra (2020) found that about a quarter of their sample in the general population in India had high levels of distress: depression (25\%), anxiety (28\%) and stress (11\%); and Mazza et al (2020) reported depression (32.4\%), anxiety (18.7\%) and stress $(27.2 \%)$ in the general population in Italy. Because of the very significant differences in the methods used by countries to cope with the pandemic, it is important to identify a range of emotional responses specific to environmental stressors in different contexts in order to organize appropriate interventions for the specific needs of the people affected.

The second aim of this study was to investigate the possible changes in depression, anxiety and stress at individual and group level during the eight weeks. Looking at the changes in the level of DASS-21 results, the present study shows that more than half of the participants experienced a change in the level of depression, anxiety and stress $(51.95 \%, 50.65 \%$ and $55.84 \%$ respectively) and that a stable pattern was observed in almost half of them (Table 4 ). This means that the hypothesis of symptom stability is partially confirmed: Although depression, anxiety and stress are relatively stable over time (Kendler et al., 2012; Lovibond, 1998), there are specific environmental experiences, particularly stressful life events in a pandemic that could have a strong transitory influence on these symptoms and could change their values. It should be noted that even in a situation such as the pandemic lockdown, there are participants who were feeling better over time. In our sample there were $7.79 \%, 12.99 \%$ and $5.84 \%$ of the participants who reported that they felt less depressed, anxious and stressed during the 8-week study period. They could be of particular interest for further research on resilience during a pandemic. Some earlier findings suggest that these young adults may have a higher potential to build and experience resilience in times like these, due to numerous social contacts, high digital literacy and skills (Masten, 2001; Werner, 1993).

In the case of the potential changes in the mean values for depression, anxiety and stress during the eight weeks, the hypothesis was confirmed, i.e. the psychological distress was higher at the beginning of the study period. The ANOVA results show that depression, anxiety and stress show significant differences in certain study waves. The decreasing trend could be observed after the first shock of all behavioral restrictions brought in the $1^{\mathrm{s}} \mathrm{t}$ wave and after the earthquakes in the $2^{\text {nd }}$ wave (Figure 1 ; Table 1 ). It is also important to mention 
that most of the differences were also in the $6^{\text {th }}$ wave. As Figure 1 shows, depression, anxiety and stress reached their lowest level in this wave due to the relaxation of all the behavioral restrictions introduced in Croatia at the beginning of the pandemic (Table 1). The Croatian population differs slightly from the world population in this pandemic, as we had to go through a number of additional traumatic experiences - earthquakes. The earthquake shook up our participants in the second week of the survey, as shown in Figure 1. This result is consistent with the study results of Roje Đapić et al. (2020), who found a statistically significant increase in anxiety levels (but not depression and stress) after the earthquake. After wave 2, a decrease in all subscale results was observed. These results may be related to the improvement of the COVID-19 situation in Croatia (Table 1) and consequently to the tendency of people to estimate the pandemic risk in their country as lower than in Europe and the world (Roje Đapić et al., 2020). It could also be due to the fact that there was more information about the virus in Croatia, as it spread much later than in China, and this knowledge about the pandemic could explain the lower psychological distress. Another explanation could be related to the fact that the spread of COVID-19 at the time the study was conducted was well-controlled by the measures of the Croatian Headquarters of Civil Protection. In this sense, an interesting finding in China was that students' anxiety was not significantly correlated with the cities or provinces in which they lived, even if they lived in cities where $73 \%$ of confirmed affected cases across China (Wang and Zhao, 2020). One of the explanations offered by the authors was the effectiveness of government policies during the time the study was conducted. Another explanation of our results could be referred to the participants age in this study. They were fourth and fifth graders and some similar studies found that older students had lower anxiety levels, were more stable and mature, and were better able to cope with emotional stress (Wang and Zhao, 2020). OdriozolaGonzáleza et al (2020) also found that sixth-year students had lower depression and stress levels compared to first year students, and fourth-year students also had lower depression levels compared to first year students.

In contrast to our results, a survey conducted by Jokić-Begić et al. (2020) among a sample of 3,500 Croatian people shows that not only are people in Croatia more depressed, anxious and under higher stress compared to the comparable data before the pandemic, but their mental health is also more affected than that of participants from other countries. Although we had samples from the same population, we came to different results. This could be due to the specific characteristics of our samples: in contrast to Jokić-Begić et al (2020), who had a more all-inclusive sample, the participants in this study were students who were invited to participate in the study. In other words, our sample is more specific and homogeneous. In addition, our sample consisted of students who participated in this project by guiding and mentoring the members who formed their online support groups. This gave them a sense of purpose in contributing to the well-being of society, which could potentially increase their resilience and maintain a relatively normal level of distress. In addition, some authors argue that social networking services such as Facebook, Twitter, TikTok, through which our students influenced a wider audience, helped to spread scientific information by encouraging people to look for trustworthy sources (Wiederhold, 2020). In this context, it is possible that our students were also protected from rumors that could lead to widespread fear, social disruption, hostility or suspicion, and a higher level of despair (Taylor, 2019). In addition, some students may perceive this situation as an opportunity to slow down their lives, focus on some neglected aspects and do things that are designed to improve their long-term well-being. It is important to mention that we have organized psychoeducation 
and support for all our participants on a weekly basis, and it has been found that education and mental health literacy in general predict a lower level of distress (Zhang, Chen and Feng, 2015). Given the continuing negative correlation between educational attainment and distress, the results of this study are not surprising. Participation in a project involving psychoeducational interventions has certainly contributed to some aspects of well-being. Similarly, preliminary results of the research mentioned above suggest that $3 \%$ of students sought and used professional psychological help during the coronavirus pandemic, but many more estimated that they would need it soon ( $27 \%$ perhaps, $8 \%$ likely, 3\% certain) ( JokićBegić et al., 2020). The combination of the survey and preventive intervention (as in the current project) is also in line with the recommendations of the WHO on low-intensity psychological interventions by trained paraprofessionals in a pandemic-like situation (Dawson et al., 2015).

There are few strengths and limitations of this study. The main precursor of this research is its longitudinal study design, which provides a clearer insight into some aspects of psychological functioning over time. It is an early study that provides the opportunity to track the emotional impact of the COVID pandemic in university students, and because it is a longitudinal panel study, we have the opportunity to analyze the long-term effects. Due to limitations, our results do not provide insight into the mechanisms by which COVID -19related stress alters the level of mental stress in our sample. Moreover, this is a study conducted on the relatively small sample of students, so that in the future the same pattern of research and intervention program could include participants from the non-student population to obtain more general results.

\section{CONCLUSIONS}

The present study examined the psychological distress in the university students during the 8-week period of the COVID -19 pandemic lockdown. Due to the very important differences in the methods used by different countries to deal with the pandemic, as well as global changes in virus behavior, our results show the importance of the longitudinal approach to the study of the topic. Considering that this current health crisis will most likely have longterm effects, longitudinal research and intervention studies are needed to obtain a clear picture of the psychological impact of the COVID pandemic. 


\section{DATA AVAILABILITY STATEMENT}

The study materials and data are available upon request from the corresponding author.

\section{ETHICS STATEMENT}

The studies involving human participants were reviewed and approved by the Ethics Committee of the Department of Psychology at the University of Zadar. The participants provided their written informed consent to participate in this study.

\section{AUTHOR CONTRIBUTIONS}

AVP, MBS and PS were involved in the conceptualization of the project and acquisition and analysis of the data. MBS and PS conducted data collection and data processing and AVP wrote and revised the manuscript. All authors contributed to the article and approved the submitted version.

\section{ACKNOWLEDGMENTS}

The authors are grateful and would like to thank the university students for their participation in this study.

\section{REFERENCES}

Beiter R. M., Nash, R., McCardy, M., Rhoades D., Linscomb M., Clarahan M. M., and Sammut S. (2015). The prevalence and correlates of depression, anxiety, and stress in a sample of college students. Journal of Affective Disorders. 173, 90-96.

Brooks, S. K., Webster, R. K., Smith, L. E., Woodland, L., Wessely, S., Greenberg, N., et al. (2019). The psychological impact of quarantine and how to reduce it: rapid review of the evidence. Lancet 395, 912-920. DOI: 10.1016/S0140-6736(20)30460-8

Cao, W., Fang, Z., Hou, G., Han, M., Xu, X., Dong, J., \& Zheng, J. (2020). The psychological impact of the COVID-19 epidemic on college students in China. Psychiatry Research, 287, 112934. https://doi.org/10.1016/j.psychres.2020.112934

Dawson K. S., Bryant, R. A., Harper M., Kuowei Tay A., Rahman, A., Schafer, A., and Van Ommeren, M. (2015). Problem Management Plus (PM1): a WHO transdiagnostic psychological intervention for common mental health problems. World Psychiatry 14(3), 354-357.

de Quervain, D., Aerni, A., Amini, E., Bentz, D., Coynel, D., Gerhards, C., . . Zuber, P. (2020). The Swiss Corona Stress Study. [Preprint], https://osf.io/iqw6a 
Henry, J. D., and Crawford, J. R. (2005). The short-form version of the Depression Anxiety Stress Scales (DASS-21): Construct validity and normative data in a large non-clinical sample. British Journal of Clinical Psychology, 44(2), 227-239.

Jokić-Begić, N., Hromatko, I., Jurin, T., Kamenov, Ž., Keresteš, G., Kuterovac Jagodić, G., Lauri Korajlija, A., Maslić Seršić, D., Mehulić, J., Mikac, U., Tadinac, M., Tomas, J. and Sangster Jokić, C. (2020). Kako smo? Život u Hrvatskoj u doba korone. Zagreb: Department of Psychology, University of Zagreb.

Kazmi, S. S. H., Hasan, K., Talib, S. and Saxena, S. (2020). COVID-19 and Lockdwon: A Study on the Impact on Mental Health (April 15, 2020). Available at SSRN: https://ssrn.com/abstract=3577515 or http://dx.doi.org/10.2139/ssrn.3577515

Kendler, K. S., Eaves, L. J., Loken, E. K., Pedersen, N. L., Middeldorp, C. M., Reynolds, C., Boomsma, D., Lichtenstein, P., Silberg, J., \& Gardner, C. O. (2011). The impact of environmental experiences on symptoms of anxiety and depression across the life span. Psychological Science, 22(10), https://doi.org/10.1177/0956797611417255

Kline, R. (2011). Principles and Practice of Structural Equation Modeling. New York: The Guilford Press.

Kontoangelos, K., Economou, M., and Papageorgiou, C. (2020). Mental health effects of CoViD-19 pandemic: a review of clinical and psychological traits. Psychiatry Investigation, 17(6), 491-505.

Liang, L., Gao, T., Ren, H., Cao, R., Qin, Z., Hu, Y., Li, C., \& Mei, S. (2020). Post-traumatic stress disorder and psychological distress in Chinese youths following the COVID-19 emergency. Journal of Health Psychology, 25(9), 1164-1175. https://doi.org/10.1177/1359105320937057

Lovibond, P. F., and Lovibond, S. H. (1995). The structure of negative emotional states: Comparison of the Depression Anxiety Stress Scales (DASS) with the Beck Depression and Anxiety Inventories. Behavior Research and Therapy, 33(3), 335-343.

Lovibond, P. F. (1998). Long-term stability of depression, anxiety, and stress syndromes. Journal of Abnormal Psychology, 107(3), 520-526. Masten, A. S. (2001). Ordinary magic: Resilience processes in development. American Psychologist, 56(3), 227-238.

Masten, A. S. (2001). Ordinary magic: Resilience processes in development. American Psychologist, 56(3), 227-238.

Mazza, C., Ricci, E., Biondi, S., Colasanti, M., Ferracuti, S., Napoli, C., \& Roma, P. (2020). A Nationwide Survey of Psychological Distress among Italian People during the COVID-19 Pandemic: Immediate Psychological Responses and Associated Factors. International journal of Environmental Research and Public Health, 17(9), 3165. https://doi.org/10.3390/ijerph17093165

Odriozola-González, P., Planchuelo-Gómez, Á., Irurtia, M. J., \& de Luis-García, R. (2020). Psychological effects of the COVID-19 outbreak and lockdown among students and workers of a Spanish university. Psychiatry Research, 290, 113108. https://doi.org/10.1016/j.psychres.2020.113108 
Ozamiz-Etxebarria, N., Dosil-Santamaria, M., Picaza-Gorrochategui, M., and IdoiagaMondragon, N. (2020). Stress, anxiety, and depression levels in the initial stage of the COVID-19 outbreak in a population sample in northern Spain. Cadernos de Saúde Pública, 36(4). https://doi.org/10.1590/0102-311X00054020

Rith-Najariana, L. R., Boustani, M. M., and Chorpita B. F. (2019). A systematic review of prevention programs targeting depression, anxiety, and stress in university students. Journal of Affective Disorders. 257, 568-584.

Rodríguez Rey, R., Garrido Hernansaiz, H., and Alonso Tapia, J. (2020). Coping and Resilience Are Differently Related Depending on the Population: A Comparison Between Three Clinical Samples and the General Population. International Journal of Stress Management, 27(3), 304-309. https://doi.org/10.1037/str0000156

Roje Đapić, M. and Prijatelj, K. (2020). Report on some aspects of mental health during a COVID-19 pandemic. Preliminary results. https://www.poliklinikadjeca.hr/istrazivanja/izvjestaj-neki-aspekti-mentalnog-zdravlja-za-vrijeme-pandemije-covid19-preliminarni-rezultati-istrazivanja/

Serafini G., Parmigiani B., Amerio A., Aguglia A., Sher L., and Amore M. (2020). The psychological impact of COVID-19 on the mental health in the general population. QJM: An International Journal of Medicine. 1-7.

Shanahan L., Steinhoff A., Bechtiger L., Murray A.L., Nivette A., Hepp U., Ribeaud D., and Eisner M. (2020). Emotional distress in young adults during the COVID-19 pandemic: Evidence of risk and resilience from a longitudinal cohort study. Psychological Medicine, 132.

Taylor, S. (2019). The Psychology of Pandemics: Preparing for the Next Global Outbreak of Infectious Disease. Newcastle: Cambridge Scholars Publishing.

Taylor, S., Landry, C., Paluszek, M., Fergus, T. A., McKay, D., and Asmundson, G. J. (2020). Development and initial validation of the COVID Stress Scales. Journal of Anxiety Disorders, 102232.

Verma, S., and Mishra, A. (2020). Depression, anxiety, and stress and socio-demographic correlates among general Indian public during COVID-19. International Journal of Social Psychiatry. https://doi.org/10.1177/0020764020934508

Wang, Y., Zhao, X., Feng, Q., Liu, L., Yao, Y., \& Shi, J. (2020). Psychological assistance during the coronavirus disease 2019 outbreak in China. Journal of Health Psychology, 25(6), 733737. https://doi.org/10.1177/1359105320919177

Wang, C., and Zhao, H. (2020). The Impact of COVID-19 on Anxiety in Chinese University Students. Frontiers in Psychology. 11:1168. DOI: 10.3389/fpsyg.2020.01168.

Werner, E. E. (1993). Risk, resilience, and recovery: Perspectives from the Kauai Longitudinal Study. Development and Psychopathology, 5(4), 503-515.

Wiederhold, B. K. (2020). Using social media to our advantage: Alleviating anxiety during a pandemic. Cyberpsychology, Behavior and Social Networking, 23(4), 197-198.

Zivin, K., Eisenberg, D., Gollust, S. E., and Golberstein, E. (2009). Persistence of mental health problems and needs in a college student population. Journal of Affective Disorders, 117(3), 180-185. 
Zhang, W., Chen, H., and Feng, Q. (2015). Education and psychological distress of older Chinese: Exploring the longitudinal relationship and its subgroup variations. Journal of Aging and Health, 27(7), 1170-1198. 